\title{
Skin tumour immunity: Site does matter for antigen presentation by DCs
}

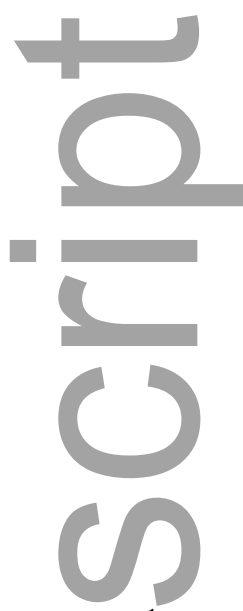

Jason Waithman ${ }^{1}$, Thomas Gebhardt ${ }^{2}$ and Sammy Bedoui ${ }^{2}$

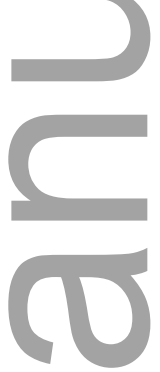

${ }^{1}$ Telethon Kids Institute, University of Western Australia, Subiaco, Australia

${ }^{2}$ Department of Microbiology and Immunology, The University of Melbourne at the Peter Doherty Institute for Infection and Immunity, Melbourne, Victoria 3000, Australia

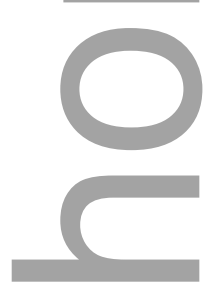

Keywords: Dendritic cells, tumour immunology, antigen presentation/processing, T cells

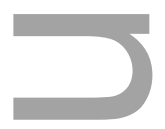

This is the author manuscript accepted for publication and has undergone full peer review but has not been through the copyediting, typesetting, pagination and proofreading process, which may lead to differences between this version and the Version of Record. Please cite this article as doi: 10.1002/eji.201646293.

This article is protected by copyright. All rights reserved. 


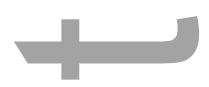

Correspondence: sbedoui@unimelb.edu.au
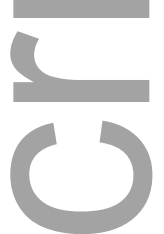

See accompanying article by Joncker et al.

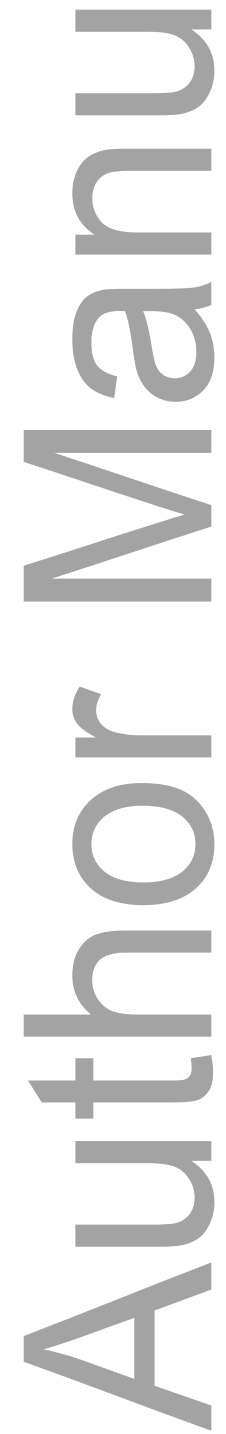

This article is protected by copyright. All rights reserved. 


\section{Abstract}

The immune system has the ability to specifically identify and eliminate tumours, but the underlying mechanisms responsible for this phenomenon are not fully understood. A study published in this issue of the European Journal of Immunology now provides new insights into this important issue. Joncker

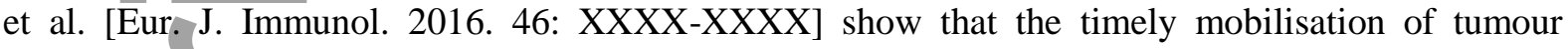
antigen-bearing dendritic cells from the periphery to the lymph nodes is critical for effective antitumour T-cell immunity, and that dendritic cells present tumour antigens much more efficiently when encountered in the skin rather than in the subcutaneous tissues.

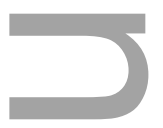

This commentary discusses Joncker et al. [Eur. J. Immunol. 2016. 46: XXXX-XXXX], who show that dendritic cells present tumour antigens much more efficiently when encountered in the skin rather than in the subcutaneous tissues.

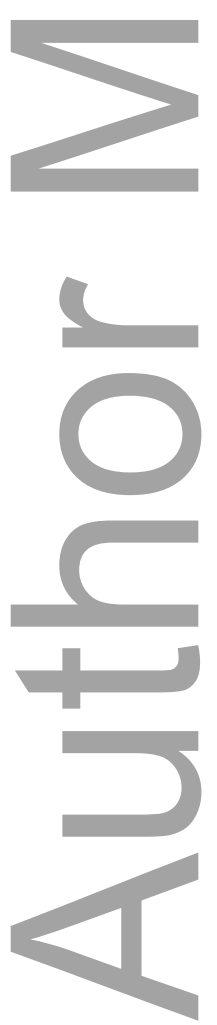

This article is protected by copyright. All rights reserved. 


\section{Subcutaneous}

tumour inoculation

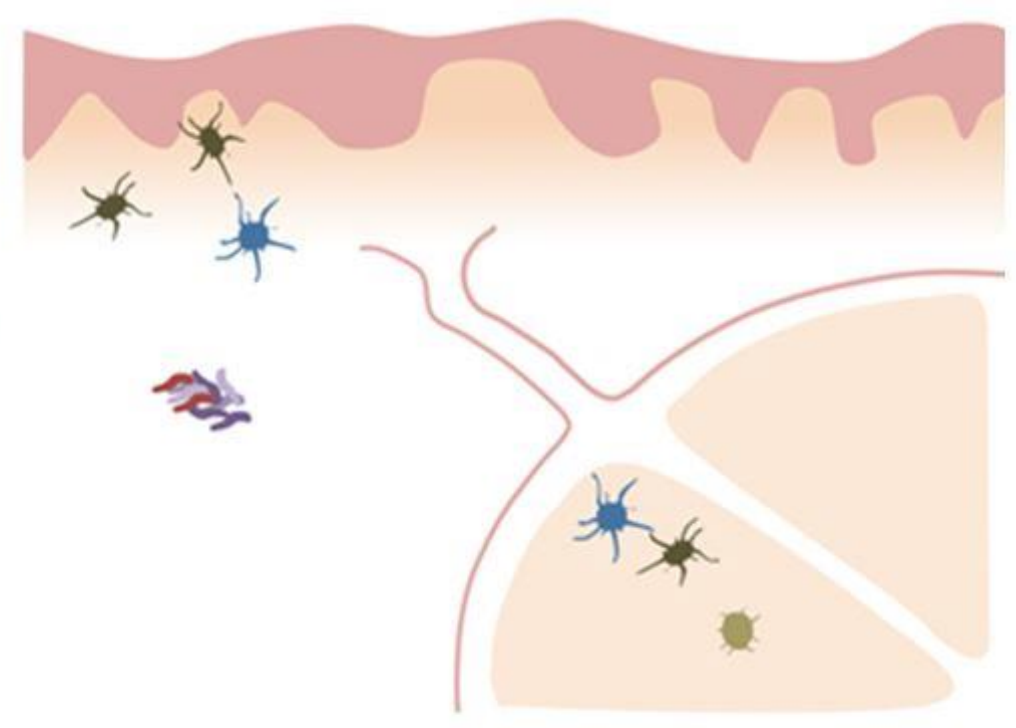

\section{Intradermal \\ tumour inoculation}
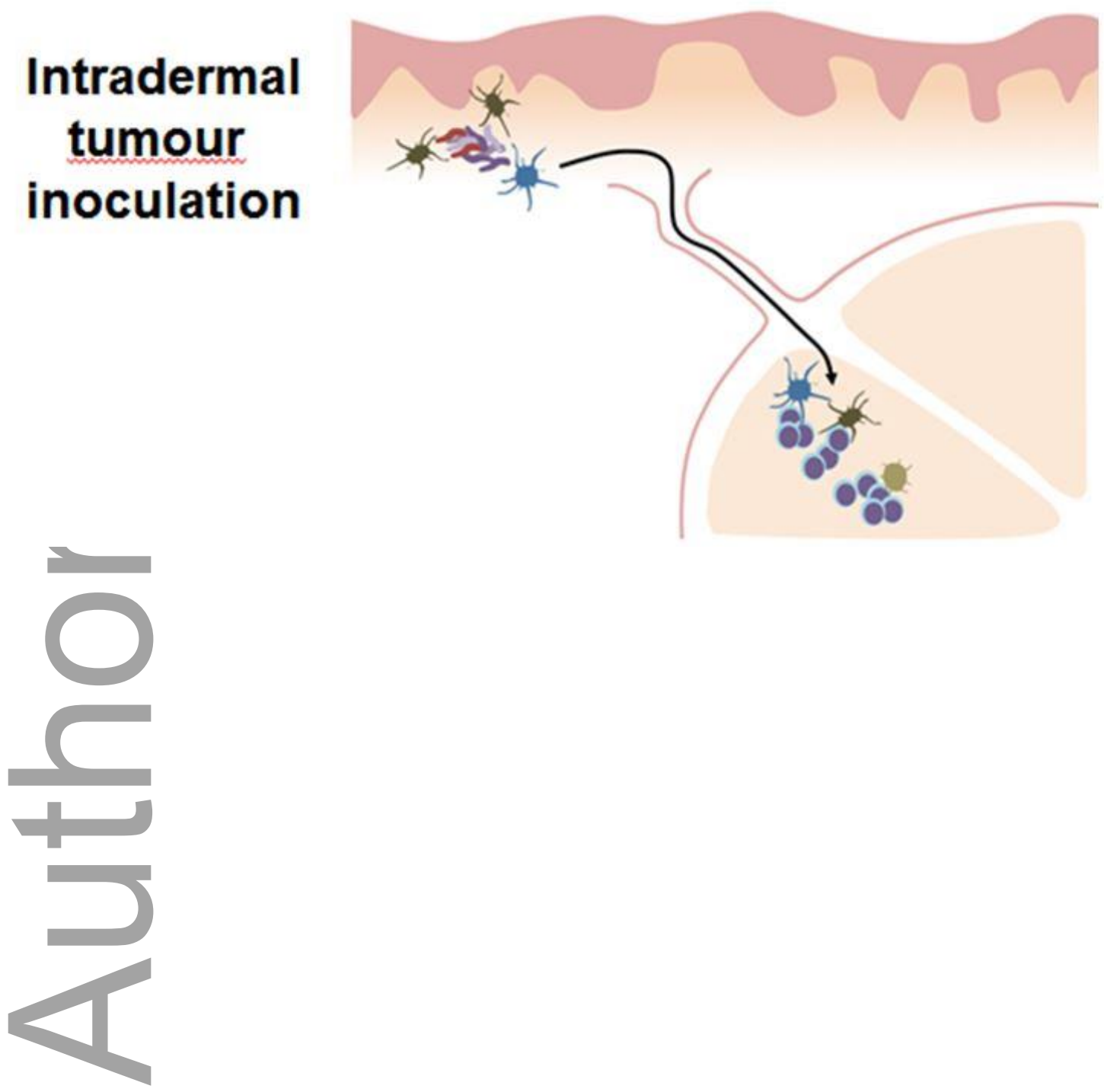
The incidence of skin tumours has increased over the past decades. Melanoma is the most dangerous form of skin cancer and novel immunotherapies harnessing $\mathrm{T}$ cells have emerged as effective therapies for the treatment of this often-fatal disease. Successful outcomes are apparent, but tumours often relapse $[1,2]$. To improve patient outcomes, it is absolutely vital to understand how T-cell immunity against cutaneous tumours is generated.

Scientists have routinely utilised small animal models with transplanted tumour cells to dissect the interplay between skin cancer and the host immune response. One of the most commonly utilised models involves subcutaneous delivery of tumour cells. This robust model results in rapid tumour formation in the connective tissue layer located in between the dermis and the fascia that encase the deeper tissues [3]. This model continues to be widely used for the preclinical evaluation of possible interventions and therapeutics [4]. A caveat of this model, however, is that very few human cancers originate within the subcutaneous tissue. Moreover, primary tumour growth in this model occurs at a location that is distal to the epidermal and dermal network of dendritic cells (DCs) required to activate tumour-specific T-cell immunity. Studies over the past decades have demonstrated that dermal implantation of tumour cells favours spontaneous clearance[5-8]. By contrast, subcutaneous inoculation is often associated with progressive growth and fatal dissemination of the same tumour cells. Importantly, why subcutaneously inoculated tumours are poorly controlled by the immune system remains a central unanswered question. Addressing this important point, Joncker et al. [9] show in this issue of the European Journal of Immunology that the site of tumour inoculation in mice dramatically impacts on the capacity of DCs to initiate protective T-cell immunity.

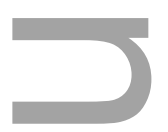

To compare how the site of tumour inoculation impacts on immune control, Joncker et al. [9] measured tumour growth in mice injected intradermally (i.d.) or subcutaneously (s.c.) with recombinant EL4 T-cell lymphoma cells. While the tumour cells grew substantially in the 
subcutaneous tissue and formed a large tumour over the 16-day interval investigated, injection of the same tumour cells into the dermis did not lead to a clinically appreciable mass. Comparing tumour growth between $R a g 2^{-/}$mice and mice in which $\mathrm{CD} 4^{+}$and/or $\mathrm{CD} 8^{+} \mathrm{T}$ cells were depleted, the authors determined that the i.d. inoculated tumour cells were rejected by $\mathrm{CD} 8^{+} \mathrm{T}$ cells, and that $\mathrm{CD} 4^{+} \mathrm{T}$ cells could also control tumour development, at least to some degree, in the absence of $\mathrm{CD}^{+} \mathrm{T}$ cells. Contrasting with this effective level of T-cell-mediated control, the s.c. tumour grew rapidly irrespective of the presence of $\mathrm{T}$ cells. A first clue as to how administration of the same tumour cells into different skin-associated sites could result in such differences in the level of T-cell-mediated control came from adoptive T-cell transfer experiments. Here, the authors injected tumour-bearing mice with tumour-specific $\mathrm{CD} 4^{+}$and $\mathrm{CD} 8^{+} \mathrm{T}$ cells and 16 hours later assessed whether the transferred T cells upregulated the early activation marker CD69 in tumour draining lymph nodes. This approach serves as a very sensitive readout system for in vivo antigen presentation [10]. Tumour-specific T cells increased expression of CD69 when injected into mice on day two or day eight after i.d. tumour challenge, indicating that tumour antigen was efficiently presented in the tumour-draining LN. However, transferred T cells only increased CD69 expression in mice given the tumour via the s.c. route eight, but not two days earlier. Successful control of i.d. tumours thus correlated with early onset in vivo antigen presentation, while delayed antigen presentation was associated with poor control of tumours in the subcutaneous tissue.

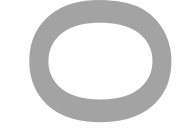

Given the critical role of DCs in presenting antigen to $\mathrm{T}$ cells in lymphoid tissues, the authors reasoned that the two alternate routes of tumour inoculation affected antigen presentation by DCs in a differential manner. DCs are a heterogeneous group of bone marrow-derived phagocytic cells, which populate both peripheral tissues and lymphoid organs. They not only differ with regards to location and phenotype, but also vary in their respective capacities to present antigen. All subpopulations of DCs have the capacity to stimulate $\mathrm{CD} 4^{+} \mathrm{T}$ cells through the presentation of exogenous antigen on 
MHC class II molecules. This contrasts with the activation of tumour-specific $\mathrm{CD} 8^{+} \mathrm{T}$ cells, which is limited to a cohort of DCs capable of introducing exogenous antigens into the MHC class I pathway. This process is referred to as cross-presentation. Lymphoid tissue-resident $\mathrm{CD} 8^{+} \mathrm{DCs}$, and $\mathrm{CD} 103^{+}$ DCs immigrating into lymph nodes from peripheral tissues, such as skin and gut, have excellent capacities to cross-present foreign and self-antigens [10]. To assess the relative capacity of these different DC subsets to cross-present tumour-derived antigen, Joncker et al. [9] isolated CD8 ${ }^{+}$DCs, $\mathrm{CD}_{103^{+}} \mathrm{DCs}$, lymphoid tissue-resident $\mathrm{CD} 8^{\text {neg }}$ DCs and migratory $\mathrm{CD} 103^{\text {neg }}$ DCs from mice inoculated via the i.d. or s.c. route. Upon co-culturing the DCs with tumour-specific $\mathrm{CD}^{+} \mathrm{T}^{\mathrm{T}}$ cells, it became evident that DCs isolated two days after i.d. tumour inoculation efficiently cross-presented tumour antigen to $\mathrm{CD}^{+} \mathrm{T}$ cells, whereas DCs from mice harbouring s.c. tumours failed to do so. Both $\mathrm{CD}_{103^{+}}$and $\mathrm{CD} 103^{\text {neg }}$ DC populations were highly efficient at cross-presenting i.d. tumour antigen. At a later time point (day 8), DCs from both groups of mice had equivalent abilities to cross-present tumour antigen, which aligns with the finding that in vivo antigen presentation was delayed in mice burdened with the s.c. tumour.

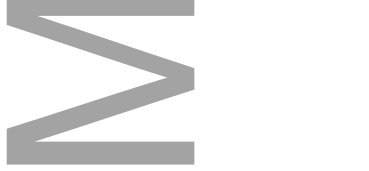

While cross-presenting DCs were traditionally identified by their expression of CD8 and CD103, it is now clear that not all CD8-expressing DCs belong to the lineage specialised in cross-presentation [11] and, conversely, that not all cross-presenting DC express CD8 or CD103. The latter aspect is particularly relevant in human DCs. The XC-chemokine receptor 1 (XCR1) has now been identified as a marker that unifies the identification of cross-presenting DCs across different tissues and species [12]. In a transplant model of cutaneous melanoma where tumour growth is constrained to the skin, it has been demonstrated that two migratory populations, defined as $\mathrm{CD} 103^{\text {neg }} \mathrm{XCR}^{+}$and $\mathrm{CD} 103^{+} \mathrm{XCR} 1^{+}$, excel at cross-presenting melanoma-derived antigen, with the $\mathrm{CD} 103^{\text {neg }} \mathrm{XCR} 1^{+} \mathrm{DCs}$ surprisingly dominating this process [13]. It is possible that a proportion of the cross-presenting migratory CD103 ${ }^{\text {neg }}$ DC population identified by Joncker et al. [9] expressed XCR1 and that these 
cells were responsible for the induction of the $\mathrm{CD} 8^{+} \mathrm{T}$-cell response against the tumour. This would be consistent with the observation that anti-tumour $\mathrm{CD} 8^{+} \mathrm{T}$-cell immunity is severely impaired in mice lacking XCR1 ${ }^{+}$DCs due to the absence of the transcription factor Batf3 $[14,15]$.

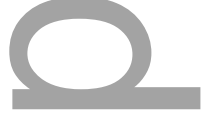

To date, sparse information exists on the identity of the DC subpopulations that proficiently present tumour antigens to $\mathrm{CD} 4^{+} \mathrm{T}$ cells. Joncker et al. [9] showed that during the early phase of i.d. tumour development the CD103 ${ }^{\text {neg }}$ DCs were the only DC subtype capable of inducing tumour-specific CD4 ${ }^{+}$ T-cell activation, whereas none of the DC subpopulations from mice bearing s.c. tumours could effectively drive $\mathrm{CD} 4^{+}$T-cell proliferation ex vivo. At a later time point, MHC class II class-restricted antigen presentation by the migratory $\mathrm{CD}_{103}{ }^{+}$and $\mathrm{CD} 103^{\text {neg }}$ DC populations was observed in both the intradermal and subcutaneous model, indicating that the lack of early presentation was not due to an impairment of DC migration or lymphatic drainage per se. Regarding lymphoid tissue-resident DCs, only the $\mathrm{CD} 8^{\text {neg }} \mathrm{DC}$ s isolated from the lymph nodes draining s.c. tumours presented antigen to $\mathrm{CD} 4^{+}$ $\mathrm{T}$ cells. These results mirrored the overall kinetics of in vivo tumour antigen presentation to $\mathrm{CD} 8^{+} \mathrm{T}$ cells, indieating a similarly delayed activation of $\mathrm{CD} 4^{+}$and $\mathrm{CD} 8^{+} \mathrm{T}$ cells after s.c. tumour inoculation. Certain $\mathrm{CD}^{+} \mathrm{T}$-cell subsets, such as IL-9-producing $\mathrm{CD}^{+} \mathrm{T}$ cells, have been proposed to promote anti-tumour responses in vivo $[16,17]$. It will therefore be important to determine in future studies whether the varying antigen presentation kinetics and the route of inoculation also impact on the quality and overall protective potential of the ensuing $\mathrm{CD} 4^{+} \mathrm{T}$-cell response.

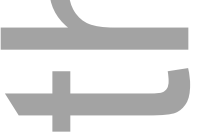

A series of interesting experiments presented by Joncker et al. [9] involved challenging tumourburdened mice with a secondary tumour at a distant site. Mice previously inoculated with an i.d. tumour were fully capable of controlling a nascent s.c. tumour, implying that $\mathrm{T}$ cells can enter the subcutaneous space and exert effective tumour control in this anatomical niche. By contrast, a second 
s.c. tumour progressed unmitigated in mice previously inoculated with a s.c. tumour. These results corroborate that tumour-specific T-cell immunity was only protective after i.d. inoculation. In additional experiments, the authors challenged mice with s.c. tumours followed by a secondary i.d. challenge. Intriguingly, while the secondary i.d. tumours were controlled, the growth of the primary tumour was only controlled when the secondary tumour was introduced early ( 2 days) but not late (6 days). These results further emphasise the importance of the T-cell response kinetics relative to the stage of tumour growth, suggesting that the effector T-cell response primed in this model may become inefficient once a certain threshold of tumour mass is reached.

Taken together, the work from Joncker et al. [9] links antigen presentation kinetics by DCs to the well-described phenomenon that tumours in certain anatomical locations are poor at inducing protective T-eell immunity. This is an important step forward in understanding tumour immunity that warrants further studies to shed more light on the quantitative and qualitative aspects of T-cell responses generated after tumour challenge in defined anatomical locations. Such knowledge will also be important to assess the relevance of varying experimental tumour models in replicating the clinically highly diverse tumour manifestations in humans.

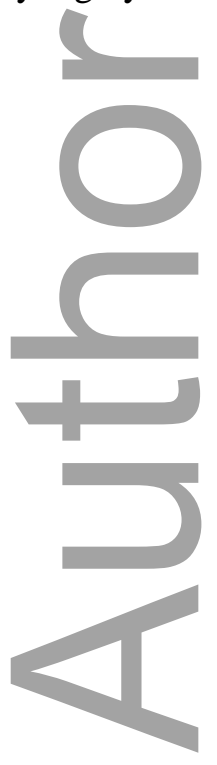

This article is protected by copyright. All rights reserved. 


\section{Acknowledgments}

Our work is supported by the National Health and Medical Research Council of Australia (J.W., T.G. and S.B.).
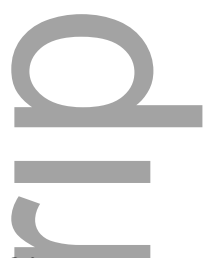

\section{Conflict of interest}

The authors declare no financial or commercial conflict of interest.

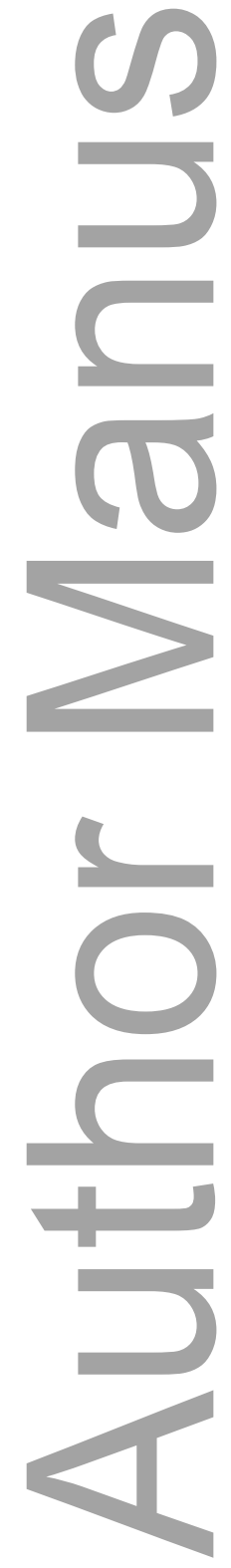

This article is protected by copyright. All rights reserved. 


\section{Figure Legend}

Figure 1. Differential kinetics of antigen presentation by DCs and resulting tumour control following intradermal or subcutaneous inoculation of tumour cells. Following subcutaneous tumour cell inoculation of mice, Joncker at al. [7] observed that migratory DCs can only make tumour antigen available for T-cell priming in lymph node 6 days after inoculation. These kinetics result in delayed and/or reduced tumour-specific T-cell priming, which in turn fails to control the tumour. Conversely, presentation of tumour antigen following intradermal inoculation of the same tumour cells occurs rapidly. The relatively faster, and perhaps stronger, effector T-cell response contributes to better tumour control.

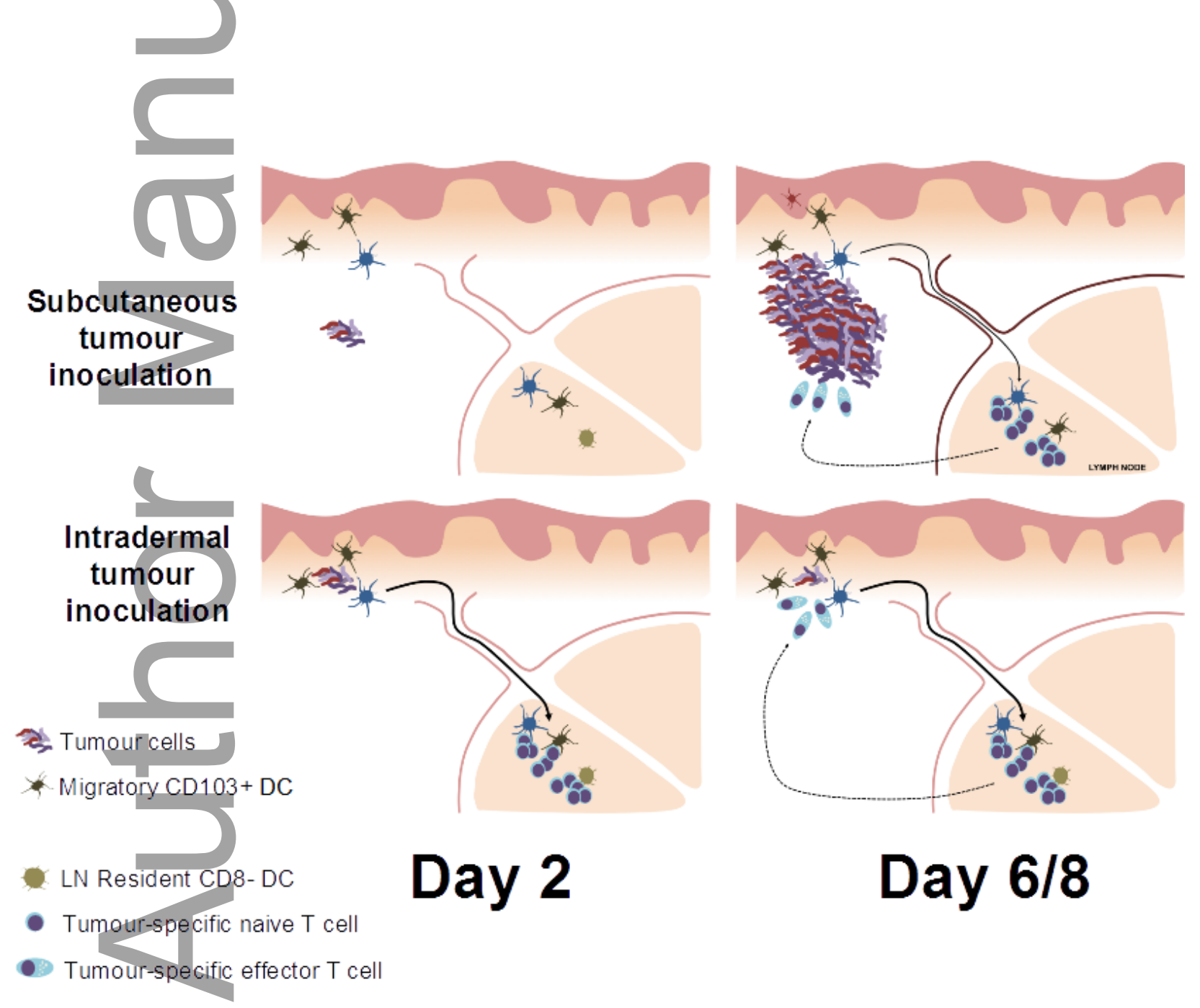

This article is protected by copyright. All rights reserved. 


\section{Reference}

1 Rosenberg, S. A., Raising the bar: the curative potential of human cancer immunotherapy. SciTrans/Med 2012. 4: 127ps128.

2 Larkin, J., Hodi, F. S. and Wolchok, J. D., Combined Nivolumab and Ipilimumab or Monotherapy in Untreated Melanoma. N Engl J Med 2015. 373: 1270-1271.

3 Holland, E. C., Mouse Models of Human Cancer. Hoboken, NJ: Wiley-Liss 2004.

4 Budhu, S., Wolchok, J. and Merghoub, T., The importance of animal models in tumor immunity and immunotherapy. Curr Opin Genet Dev 2014. 24: 46-51.

5 Gross, L., Intradermal immunization of $\mathrm{C} 3 \mathrm{H}$ mice against a sarcoma that originated in an animal of the same line. Cancer Research 1943. 3: 326-333.

6 Gross, L., Feldman, D. G., Ehrenreich, T., Dreyfuss, Y. and Moore, L. A., Comparative studies of subcutaneous and intradermal leukemic tumors in guinea pigs. Cancer Res 1973. 33: 293301

7 Dunham, W. B. and Waymouth, C., Intradermal transplantation in mice of small numbers of sarcoma cells followed by tumor growth and regression. Cancer Res 1976. 36: 189-193. Intradermal injection, as opposed to subcutaneous injection, enhances immunogenicity and suppresses tumorigenicity of tumor cells. Cancer Res 2003. 63: 2145-2149.

9 Joncker, N. T., Bettini, S., Boulet, D., Guiraud, M. and Guerder, S., The site of tumor development determines immunogenicity via temporal mobilization of antigen laden dendritic cells in draining lymph nodes. Eur J Immunol 2015.

10 Bedoui, S., Whitney, P. G., Waithman, J., Eidsmo, L., Wakim, L., Caminschi, I., Allan, R. S., Wojtasiak, M., Shortman, K., Carbone, F. R., Brooks, A. G. and Heath, W. R., Crosspresentation of viral and self antigens by skin-derived CD103+ dendritic cells. Nat Immunol 2009. 10: 488-495.

11 Bar-On, L., Birnberg, T., Lewis, K. L., Edelson, B. T., Bruder, D., Hildner, K., Buer, J., Murphy, K. M., Reizis, B. and Jung, S., CX3CR1+ CD8alpha+ dendritic cells are a steady-state population related to plasmacytoid dendritic cells. Proc Natl Acad Sci U S A 2010. 107: 14745-14750.

12 Dorner, B. G., Dorner, M. B., Zhou, X., Opitz, C., Mora, A., Guttler, S., Hutloff, A., Mages, H. W., Ranke, K., Schaefer, M., Jack, R. S., Henn, V. and Kroczek, R. A., Selective expression of the chemokine receptor XCR1 on cross-presenting dendritic cells determines cooperation with CD8+ T cells. Immunity 2009. 31: 823-833.

This article is protected by copyright. All rights reserved. 
13 Wylie, B., Seppanen, E., Xiao, K., Zemek, R., Zanker, D., Prato, S., Foley, B., Hart, P. H., Kroczek, R. A., Chen, W. and Waithman, J., Cross-presentation of cutaneous melanoma antigen by migratory XCR1CD103 and XCR1CD103 dendritic cells. Oncoimmunology 2015. 4: e1019198.

14 Hildner, K., Edelson, B. T., Purtha, W. E., Diamond, M., Matsushita, H., Kohyama, M., Calderon, B., Schraml, B. U., Unanue, E. R., Diamond, M. S., Schreiber, R. D., Murphy, T. L. and Murphy, K. M., Batf3 deficiency reveals a critical role for CD8alpha+ dendritic cells in cytotoxic T cell immunity. Science 2008. 322: 1097-1100.

15 Bachem, A., Hartung, E., Guttler, S., Mora, A., Zhou, X., Hegemann, A., Plantinga, M., Mazzini, E., Stoitzner, P., Gurka, S., Henn, V., Mages, H. W. and Kroczek, R. A., Expression of XCR1 Characterizes the Batf3-Dependent Lineage of Dendritic Cells Capable of Antigen Cross-Presentation. Front Immunol 2012. 3: 214.

16 Purwar, R., Schlapbach, C., Xiao, S., Kang, H. S., Elyaman, W., Jiang, X., Jetten, A. M., Khoury, S. J., Fuhlbrigge, R. C., Kuchroo, V. K., Clark, R. A. and Kupper, T. S., Robust tumor immunity to melanoma mediated by interleukin-9-producing T cells. Nat Med 2012. 18: 1248-1253.

17 Lu, Y., Hong, S., Li, H., Park, J., Hong, B., Wang, L., Zheng, Y., Liu, Z., Xu, J., He, J., Yang, J., Qian, J. and Yi, Q., Th9 cells promote antitumor immune responses in vivo. J Clin Invest 2012. 122: 4160-4171.

See accompanying article:

http://dx.doi.org/10.1002/eji.201545797

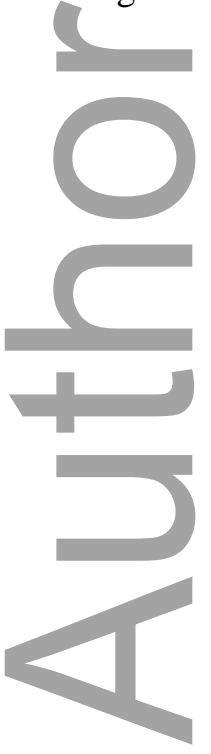

This article is protected by copyright. All rights reserved. 


\section{University Library}

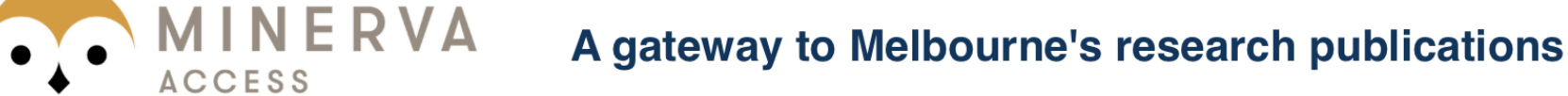

Minerva Access is the Institutional Repository of The University of Melbourne

Author/s:

Waithman, J;Gebhardt, T;Bedoui, S

Title:

Skin tumor immunity: Site does matter for antigen presentation by DCs

Date:

2016-03-01

Citation:

Waithman, J., Gebhardt, T. \& Bedoui, S. (2016). Skin tumor immunity: Site does matter for antigen presentation by DCs. EUROPEAN JOURNAL OF IMMUNOLOGY, 46 (3), pp.543-546. https://doi.org/10.1002/eji.201646293.

Persistent Link:

http://hdl.handle.net/11343/290960 